\title{
9. The Measurements of the Viscosity of Basalt Glass at High Temperatures, $I$.
}

\author{
By Kôichi KanI. \\ Electro-technical Laboratory, Ministory of Communications, Tokyo.
}

(Comm. by S. Kôzu, M.I.A., Jan. 12, 1934.)

Method:-The viscosity of basalt glass was measured by the rotation of a cylinder immersed in the molten glass contained in an outer cylindrical pot, the pot being kept stationary. The rotation of the cylinder immersed in the viscous glass can be adjusted to a uniform angular motion. The true viscosity of the glass obtainable in finding the constants in a formula which is expressed by the load and the velocity of revolution of the cylinder, compared with those of a standardized material whose true viscosity is known by another method. As the standardized material, rice-jelly was taken in this case, because it was found much more suitable compared with syrup or glucose which has often been used by the previous investigators, as no thin film was formed on the surface of the jelly during the experiment. A fuller description regarding the technics of the apparatus modified by us will be given in another paper, because the space of this publication is limited. Here is only a photograph shown to give a general idea of the apparatus (Fig. 1).

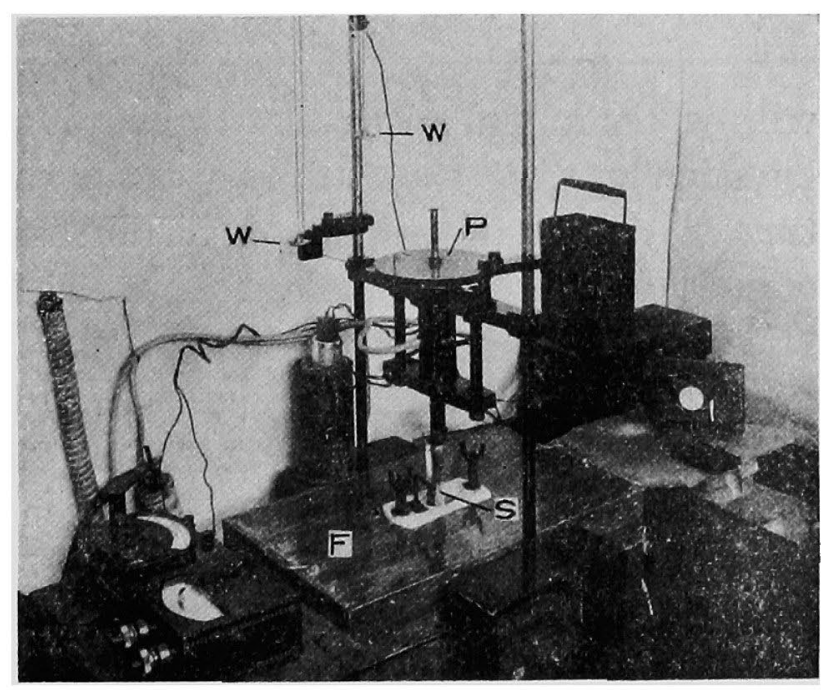

Fig. 1. W, load; F, furnace; S, stirrer ; $\mathrm{P}$, rotating plane.

Test of the accuracy of the present method:-In order to examine the accuracy of the results obtainable by the present method, the viscosity of glutinous rice-jelly kept at a constant temperature of $25^{\circ} \mathrm{C} \pm 0^{\circ} .02$ was first measured by a capillary-flow method and then the viscosity of the same material was determined by the present apparatus under the same condition.

The rice-jelly purified by filtering through fine silk was diluted 
TABLE I.

\begin{tabular}{|c|c|c|c|c|c|c|}
\hline & & \multirow{3}{*}{$\begin{array}{c}\begin{array}{c}\text { Distilled } \\
\text { water. }\end{array} \\
12.07\end{array}$} & \multicolumn{4}{|c|}{$\begin{array}{l}\text { Glutinous rice-jelly diluted } \\
\text { by water. }\end{array}$} \\
\hline & & & No. 1. & No. 2. & No. 3. & No. 4. \\
\hline \multirow{5}{*}{$\begin{array}{c}\text { Viscosimeter } \\
\text { with a small } \\
\text { capillary tube. } \\
25^{\circ} \mathrm{C}\end{array}$} & Time of flow in sec. & & 3276.6 & - & - & - \\
\hline & Volume in cc. & 2.98 & 2.94 & - & - & - \\
\hline & $\begin{array}{l}\text { Vol. adhered to the } \\
\text { wall in cc. }\end{array}$ & 0.02 & 0.06 & - & - & - \\
\hline & Density & 0.99707 & 1.332 & - & - & - \\
\hline & Viscosity in poises. & 0.008949 & 3.2896 & - & - & - \\
\hline \multirow{5}{*}{$\begin{array}{c}\text { Viscosimeter } \\
\text { with a large } \\
\text { capillary tube. } \\
25^{\circ} \mathrm{C}\end{array}$} & Time of flow in sec. & - & 50.6 & 1221.7 & 1165.5 & 3250.27 \\
\hline & Volume in cc. & - & 2.90 & 2.87 & 2.86 & 2.84 \\
\hline & $\begin{array}{l}\text { Vol. adhered to the } \\
\text { wall in cc. }\end{array}$ & - & 0.10 & 0.13 & 0.14 & 0.16 \\
\hline & Density & - & 1.332 & 1.401 & 1.430 & 1.458 \\
\hline & Viscosity in poises. & - & 3.2896 & 84.413 & 825.03 & 23618.0 \\
\hline
\end{tabular}

with water to make different degrees of viscosity. Fine bubbles produced by stirring were expelled by using a vacuum pump. The rice-jelly thus treated was separated into four different parts according to different viscosities, they being enumerated as Nos. 1-4 in increasing order of viscosity in the following description. The viscosity of the rice-jelly, measured by the capillary method, is given in Table I in parallel with the viscosity of distilled water at $25^{\circ} \mathrm{C}$, measured with the same capillary tube under the same condition as before.

TABLE II.

\begin{tabular}{|c|c|c|c|c|c|c|c|c|c|}
\hline \multicolumn{2}{|c|}{ Load in grammes $\left(W^{\prime}\right)$} & 2 & 2.5 & 3 & 3.5 & 4 & 5 & 6 & 8 \\
\hline \multirow{3}{*}{$\begin{array}{l}\text { Revolution per } \\
\text { minute, (S). }\end{array}$} & No. 2 & 12.99 & 19.98 & 26.97 & 31.92 & 37.84 & - & - & - \\
\hline & No. 3 & - & - & 3.56 & - & 6.19 & 8.53 & 10.87 & 15.58 \\
\hline & No. 4 & - & 一 & - & - & - & 一 & - & - \\
\hline \multicolumn{2}{|c|}{ Load in grammes $\left(W^{\prime}\right)$} & 10 & 12 & 14 & 16 & 18 & 20 & 25 & 30 \\
\hline \multirow{3}{*}{$\begin{array}{l}\text { Revolution per } \\
\text { minute, }(\mathrm{S}) .\end{array}$} & No. 2 & - & - & 一 & - & 一 & - & - & - \\
\hline & No. 3 & 19.71 & 23.44 & 28.36 & 32.79 & - & - & - & $一$ \\
\hline & No. 4 & 1.54 & 1.91 & 2.26 & 2.58 & 2.94 & 3.30 & 4.20 & 5.10 \\
\hline
\end{tabular}


No. 1.] The Measurements of the Viscosity of Basalt Glass at High Temperatures.

The uniform angular velocities, indicated by the revolutions of the cylinder immersed in the three different rice-jellies (Nos. 2-4) at $25^{\circ} \mathrm{C} \pm 0^{\circ} .02$ were measured under different loads. The results are given in Table II. If we indicate these results diagramatically, Fig. 2 is given. From the figure, it is seen that the three curves are straight and they can be expressed in the following equations :-

$$
\left.\begin{array}{c}
\mathrm{W}_{2}^{\prime}=0.0805 \mathrm{~S}_{2}+0.8916 \\
\text { for No. } 2, \\
\mathrm{~W}_{3}^{\prime}=0.4554 \mathrm{~S}_{3}+1.1254 \\
\text { for No. } 3, \\
\mathrm{~W}_{4}^{\prime}=5.6506 \mathrm{~S}_{4}+1.3036 \\
\text { for No. } 4,
\end{array}\right\}
$$

in which, $W^{\prime}$ is the load in grammes and $\mathrm{S}$ is the revolution of the cylinder per minute. The above formulae can be expressed by a general formula such as $\mathrm{W}^{\prime}=\mathrm{kS}+\mathrm{k}^{\prime}$ or as $\left(\mathrm{W}^{\prime}-\mathrm{k}^{\prime}\right)=\mathrm{kS}$, in which $\mathrm{k}^{\prime}$ is the distance from the origin of the co-ordinates to the intersection of the curve with the ordinate, physically it depends essentially on the friction of the rotation apparatus. Hence the load (W) which actually refers to the viscosity of the jelly is $\left(W^{\prime}-k^{\prime}\right)$. This value

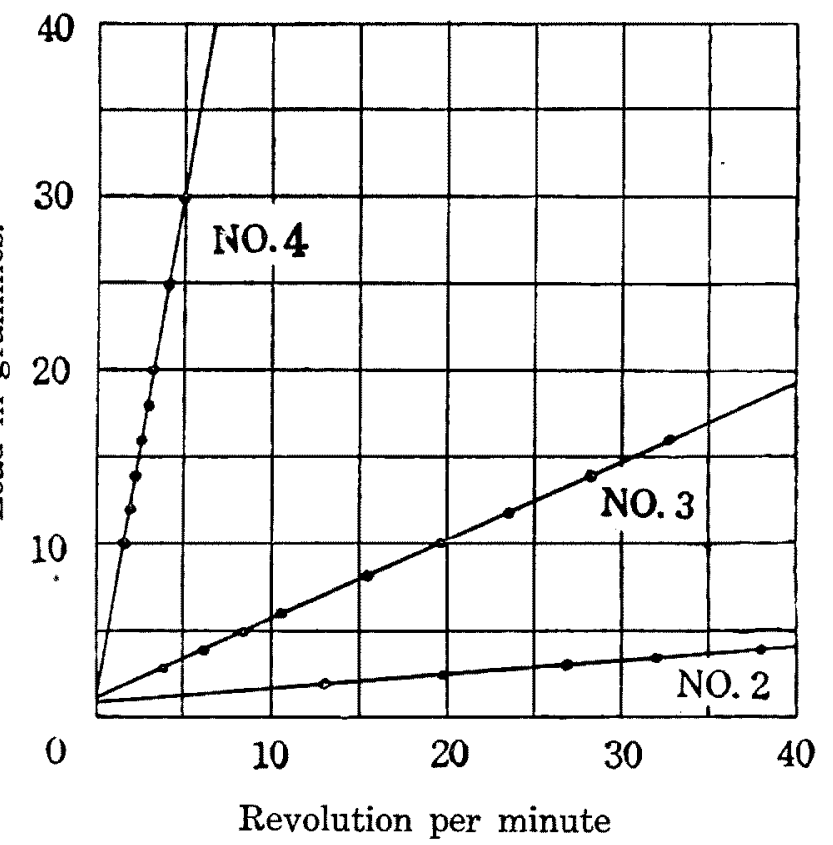

Fig. 2. Curves showing the relations between loads and revolutions for three kinds of rice-jelly.

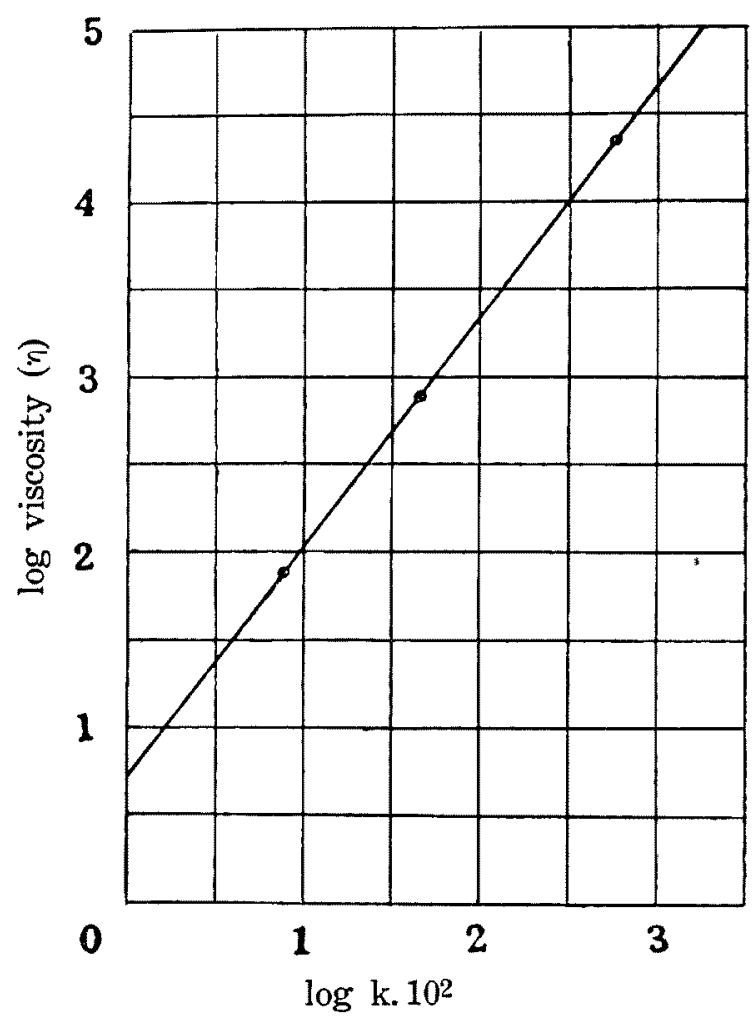

Fig. 3. Curve showing the relation $\log n$ (obtained by a viscosimeter with capillary tube) and logarithm of $\mathrm{k} \times 10^{2}$. 
can be obtained from $\mathrm{W}^{\prime}$ in Table II and $\mathrm{k}^{\prime}$ in the three equations (1) given above.

In order to see the relation between the viscosity of the rice-jelly (see Table I) and $k$ in the above formula, Fig. 3 is drawn. As is seen in the diagram, the curve refered to $\log \eta$ and $\log \mathrm{k} .10^{2}$ is practically a straight line and it can be expressed by the following equation:-

$$
\log \eta^{\prime}=1.3252 \log \mathrm{k} .10^{2}+0.7217 \text {. }
$$

To compare the viscosity $\left(\eta^{\prime}\right)$ obtained from the above equation with the viscosity ( $\eta$ ) obtained by the use of the viscosimeter with capillary tube, Table III is given. The table shows that the differences between these two results are so small as to be less than \pm one percent.

TABLE III.

\begin{tabular}{l|r|r|r|r|r|r|r|r}
\hline Rice-jelly & $\log \mathrm{k} .10^{2}$ & $\mathrm{k} \times 10^{2}$ & $\log \eta$ & \multicolumn{1}{c}{$\eta$} & $\log \eta^{\prime}$ & $\eta^{\prime}$ & $\eta-\eta^{\prime}=\Delta$ & $\Delta / \eta \times 100$ \\
\hline No. 2 & 0.9058 & 8.05 & 1.9264 & 84.413 & 1.9221 & 83.58 & 0.833 & $0.98 \%$ \\
\hline No. 3 & 1.6594 & 14.65 & 2.9165 & 825.03 & 2.9208 & 833.3 & -8.27 & $1.00 \%$ \\
\hline No. 4 & 2.7521 & 188.46 & 4.3732 & 23618.0 & 4.3689 & 23383.0 & 235 & $0.99 \%$ \\
\hline
\end{tabular}

(to be concluded) 